Research Article

\title{
Formation of 3-nitrotyrosines in carbonic anhydrase III is a sensitive marker of oxidative stress in skeletal muscle
}

\author{
Aphrodite Vasilaki ${ }^{1}$, Deborah Simpson ${ }^{2}$, Francis McArdle ${ }^{1}$, Lynne McLean ${ }^{2}$, \\ Robert J. Beynon ${ }^{2}$, Holly Van Remmen ${ }^{3}$, Arlan G. Richardson ${ }^{3}$, Anne McArdle ${ }^{1}$, \\ John A Faulkner ${ }^{4}$ and Malcolm J. Jackson ${ }^{1}$ \\ ${ }^{1}$ Division of Metabolic and Cellular Medicine, School of Clinical Sciences, University of Liverpool, \\ Liverpool, UK \\ ${ }^{2}$ Proteomics and Functional Genomics Group, Faculty of Veterinary Science, University of Liverpool, \\ Liverpool, UK \\ ${ }^{3}$ University of Texas Health Center at San Antonio and Barshop Institute for Longevity and \\ Aging Studies, San Antonio, TX, USA \\ ${ }^{4}$ Department of Molecular and Integrative Physiology Biomedical Science Research Building, \\ University of Michigan Medical School, Ann Arbor, MI, USA
}

Oxidation of skeletal muscle proteins has been reported to occur following contractions, with ageing, and with a variety of disease states, but the nature of the oxidised proteins has not been identified. A proteomics approach was utilised to identify major proteins that contain carbonyls and/or 3-nitrotyrosine (3-NT) groups in the gastrocnemius (GTN) muscles of adult (511 months of age) and old (26-28 months of age) wild type (WT) mice and adult mice lacking copper, zinc superoxide dismutase $\left(\operatorname{Sod} 1^{-1-}\right.$ mice), manganese superoxide dismutase (Sod2 $2^{+I^{-}}$ mice) or glutathione peroxidase 1 ( $\mathrm{GPx1^{-/- }}$ mice). In quiescent GTN muscles of adult and old WT mice, protein carbonylation and/or formation of 3-NT occurred in several proteins involved in glycolysis, as well as creatine kinase and carbonic anhydrase III. Following contractions, the 3-NT intensity was increased in specific protein bands from GTN muscles of both adult and old

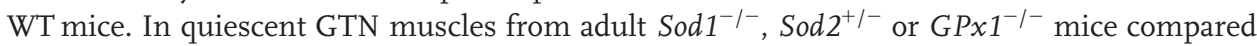
with age-matched WT mice only carbonic anhydrase III showed a greater 3-NT content. We conclude that formation of 3-NT occurs readily in response to oxidative stress in carbonic anhydrase III and this may provide a sensitive measure of oxidative damage to muscle proteins.

Keywords:

Carbonyls / 3-Nitrotyrosine / Oxidative stress / Protein oxidation / Skeletal muscle

Correspondence: Professor M. J. Jackson, Division of Metabolic and Cellular Medicine, School of Clinical Sciences, University of Liverpool, Liverpool L69 3GA, UK

E-mail: m.j.jackson@liverpool.ac.uk

Fax: +44-151-7065802

Abbreviations: CK, creatine kinase; DNPH, 2,4-dinitrophenyl hydrazine; GAPDH, glyceraldehyde-3-phosphate dehydrogenase; GTN, gastrocnemius; MW, molecular weight; 3-NT, 3-nitrotyrosine; ROS, reactive oxygen species; WT, wild type
Received: September 18, 2006

Revised: December 21, 2006

Accepted: December 21, 2006

\section{Introduction}

Skeletal muscle generates a number of reactive oxygen species (ROS) both at rest and during contractile activity (see [1] for a review) and the primary species generated appear to be superoxide and nitric oxide (NO) [2-5]. The production of superoxide and NO results in the formation of secondary species of ROS, hydroxyl radicals $[4,6]$ and peroxynitrite $[4$, 7]. Silveira et al. [8] have also reported the release of sub- 
stantial amounts of hydrogen peroxide from various intracellular sites, including the mitochondria [9]. Increased generation of ROS in muscles of humans and rodents leads to oxidative modifications of cellular components [10]. Acute changes in oxidative modification of proteins, nucleic acids, carbohydrates and lipids have been reported in skeletal muscle following periods of contractile activity [11-13]. These acute changes do not result in damage to, or necrosis of muscle fibres [3], or a loss of contractile function [14], because the highly specialised antioxidant defense and repair systems eliminate the ROS-induced oxidative modifications almost immediately (for reviews see $[15,16])$. Chronic changes in markers of oxidative modification have been described in skeletal muscle, particularly associated with ageing [17-19] and with a variety of disease states [20, 21].

ROS react either directly with proteins, or indirectly through oxidation of sugars or lipids. The oxidised sugars or lipids then reacting secondarily with protein [22]. The functional consequence of this type of modification of proteins is unclear and appears to depend upon the protein modified and the type of modification. Thus, oxidative modifications may be transient and have little functional effect on the protein or may produce permanent inactivation of the protein and loss of protein function with a subsequent accumulation of damaged proteins [22]. The complexity of the systems necessitates the identification and function of the specific proteins that are oxidised under different conditions.

Two oxidative modifications that result from the direct reaction of ROS with proteins have been studied in detail, the formation of carbonyl groups (aldehydes and ketones) and the formation of 3-nitrotyrosine (3-NT) residues. Carbonyl formation occurs following reaction of proteins with superoxide, hydroxyl radical and hydrogen peroxide [23, 24]. The nitration of tyrosine to form 3-NT residues arises from the reaction of tyrosine with peroxynitrite $\left(\mathrm{ONOO}^{-}\right)$and formation of 3-NT is generally considered an irreversible oxidative modification [23]. Following a variety of genetic, physiological and pathological perturbations of skeletal muscles, a generalised increase in protein carbonyl content and increased formation of 3-NT have been reported [12, 17, 20, 25]. Despite these reports, the specific proteins that undergo these modifications, or the susceptibility of individual proteins to oxidative modification have not been determined. For gastrocnemius (GTN) muscles of the mouse, a proteomic approach was used to identify the proteins that contained carbonyls and/or 3-NT groups. Subsequently, the amount and the pattern of oxidative modification were examined to determine which proteins were altered in GTN muscles of adult and old WT mice at rest, following a contraction protocol and in GTN muscles of adult mice deficient in key enzymes for ROS regulation, copper, zinc superoxide dis-

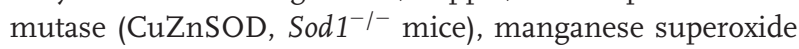
dismutase (MnSOD, Sod2 $2^{+/-}$mice) or glutathione peroxidase 1 ( $G P \times 1^{-1-}$ mice). We hypothesised that: (i) relatively few proteins would be oxidised in quiescent GTN muscles of adult WT mice; (ii) these and additional proteins would undergo increased oxidative modifications in (a) quiescent muscles of old WT mice, (b) mice with defective antioxidant defences, and (c) adult WT mice following a demanding contraction protocol.

\section{Materials and methods}

\subsection{Chemicals}

All chemicals and equipment used during 2-DE were purchased from BioRad (Hemel Hempstead, UK). The antibody against 3-NT was obtained from Cayman Chemical (Ann Arbor, MI, USA). Antidinitrophenyl-keyhole limpet hemocyanin conjugate (anti-DNP-KLH) antiserum was obtained from Molecular Probes (Eugene, OR, USA). 2,4-Dinitrophenyl hydrazine (DNPH), secondary antisera conjugated to HRP and all other reagents (analytical grade) were obtained from Sigma (Dorset, UK).

\subsection{Mice}

The studies used male adult (5-11 months) C57Bl/6J, Sod $1^{-/-}$,

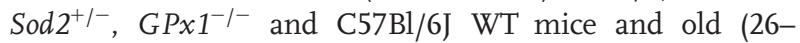
28 months) WT mice. Details regarding the generation and characterisation of the knockout mouse models have been previously described [26-29]. The Sod $1^{-1-}$ mice were originally produced in the CD1 strain, and have been backcrossed onto the C57BL/6J genetic background for at least 12 generations (B6-Sod $1^{\text {tm1Cie }}$. The Sod2 ${ }^{+/-}$mice were also originally produced in the CD1 strain, and have been backcrossed onto the C57BL/6J genetic background for 14 generations (B6Sod2 ${ }^{\text {tm1Cie }}$. GPX $1^{-1-}$ mice used in this study were originally generated in the 129Sv/J strain, and were backcrossed for ten generations onto the C57BL/6J background. Mice were anesthetised with pentobarbitone sodium with an initial dose of $65 \mathrm{mg} / 100 \mathrm{~g}$ of body mass via an intraperitoneal injection. Supplemental doses were administered as required to maintain a depth of anaesthesia sufficient to prevent response to tactile stimuli. Upon completion of an experiment on a given mouse, the mouse was euthanised by an overdose of the anaesthetic. Immediately following euthanisation, muscles were removed quickly and frozen in liquid nitrogen. Muscles were stored at $-70^{\circ} \mathrm{C}$ until analysis.

\subsection{Isometric contraction protocol}

Adult (5-11 months) and old (26-30 months) WT mice were anaesthetised and subjected to an isometric contraction protocol as previously described [30]. Briefly, the hind limb musculature were subjected to a 15-min period of electrical contractions via surface electrodes using a $100 \mathrm{~Hz}$ pulse train at $\sim 70 \mathrm{~V}$ for $0.5 \mathrm{~s}$ every $4 \mathrm{~s}$ with a pulse width of $0.2 \mathrm{~ms}$. The GTN muscles were then dissected, rapidly frozen in liquid nitrogen and stored at $-70^{\circ} \mathrm{C}$ until analysis. 


\subsection{Detection of proteins with carbonyl groups and 3-NT by 2-DE}

Protein extracts were prepared by homogenisation of muscles in $5 \% \mathrm{v} / \mathrm{v} \beta$-mercaptoethanol containing Complete $^{\mathrm{TM}}$ EDTA-free protease inhibitor cocktail (Roche Diagnostics, Mannheim, Germany) followed by centrifugation at $10000 \times \mathrm{g}$ for $10 \mathrm{~min}$ at $4^{\circ} \mathrm{C}$. Protein content of samples was determined by using the Lowry assay [31]. Two hundred and fifty micrograms of total cellular protein extract was reconstituted in $185 \mu \mathrm{L}$ of ReadyPrep rehydration/sample buffer (8 $\mathrm{M}$ urea, 2\% CHAPS, 50 mM DTT, 0.2\% w/v Bio-Lyte ${ }^{\circledR}$ 3/ 10 ampholytes and trace of Bromophenol Blue; BioRad) and applied to $11 \mathrm{~cm}, \mathrm{pH} 3-10$ IPG strips (BioRad). IPG strips were actively rehydrated at $50 \mathrm{~V}$ for $16 \mathrm{~h}$. Following rehydration, samples on IPG strips were isoelectrically focused using a Protean IEF cell (BioRad) according to the manufacturer's instructions. All focusing steps were performed at $20^{\circ} \mathrm{C}$.

For the detection of proteins containing 3-NT, proteins resolved in the first dimension strips were reduced and alkylated prior to second-dimensional electrophoresis. Strips were incubated for $10 \mathrm{~min}$ in equilibration buffer I (6 M urea, 2\% w/v SDS, 0.375 M Tris- $\mathrm{HCl}$ (pH 8.8), 20\% v/v glycerol and 2\% w/v DTT; BioRad) followed by a $10 \mathrm{~min}$ incubation in equilibration buffer II $(6 \mathrm{M}$ urea, $2 \% \mathrm{w} / \mathrm{v} \mathrm{SDS}$, $0.375 \mathrm{M}$ Tris- $\mathrm{HCl}$ ( $\mathrm{pH} 8.8$ ), $20 \% \mathrm{v} / \mathrm{v}$ glycerol and $2.5 \% \mathrm{w} / \mathrm{v}$ iodoacetamide; BioRad).

For the detection of proteins containing carbonyl groups, proteins on the IPG strips were immediately derivatised with DPNH as previously described [32]. Briefly, following IEF, strips were placed in $15 \mathrm{~mL}$ test tubes and incubated for $20 \mathrm{~min}$ in $2 \mathrm{~N} \mathrm{HCl}$ with $10 \mathrm{mM} \mathrm{DNPH}$ at $25^{\circ} \mathrm{C}$ for $20 \mathrm{~min}$. After the reaction, the samples were washed with $2 \mathrm{M}$ Tris Base/30\% glycerol for 15 min. Sample IPG strips were then reduced and alkylated as described above.

Duplicate samples of the derivatised/nonderivatised proteins were separated by SDS-PAGE using a Criterion system (BioRad). After laying the strip on top of a 10.5-14\% gradient polyacrylamide gel (BioRad) and sealing it with agarose, electrophoresis was carried out for $\sim 60 \mathrm{~min}$ at 200 V. Following electrophoresis, proteins on one gel were subjected to Western blotting and analysed for protein carbonyl or 3-NT content using anti-DNP-KLH or anti-3-NT antisera, respectively. Proteins on the other gel were stained overnight with $0.1 \% \mathrm{w} / \mathrm{v}$ CBB R-250 in $40 \% \mathrm{v} / \mathrm{v}$ methanol, $10 \% \mathrm{v} / \mathrm{v}$ acetic acid and were visualised by background destaining in a solution of $10 \% \mathrm{v} / \mathrm{v}$ acetic acid, $40 \% \mathrm{v} / \mathrm{v}$ methanol.

Detection of carbonylated proteins was performed by using Oxyblot ${ }^{\mathrm{TM}}$ protein oxidation detection kit (Chemicon International, Temecula, CA, USA). Briefly, following derivatisation with $\mathrm{DNPH}$, membranes were incubated with primary and secondary antibodies in PBS containing $0.5 \%$ Tween-20 and 1\% w/v BSA. DNP-derivatised proteins were visualised using a Chemi-Doc System (BioRad) and quanti- fied using Quantity-one software (BioRad). To determine band specificity, negative controls (DNPH nonderivatised samples) were also included in the gels.

Detection of 3-NT on the Western blots was undertaken by using a mouse mAb (Cat \# 189542). Bands were again visualised using a BioRad Chemi-Doc System (BioRad).

All Western blots produced following 2-DE for the detection of either protein carbonyls or proteins containing 3-NT, were subjected to a $60 \mathrm{~s}$ exposure in order to minimise exposure errors and avoid band saturation. In order to correlate the protein stain with the Western blot, the gels and blots were superimposed onto each other according to molecular weight $(\mathrm{MW})$ and $\mathrm{pI}$ range that were extrapolated based on the dimensions of the gels.

\subsection{Characterisation of proteins by MALDI-TOF MS}

Excised gel spots were digested with trypsin and spotted onto a MALDI target plate [33]. MALDI-TOF mass spectra were acquired on a M@LDI R mass spectrometer (Waters, Manchester, UK). PMF was carried out using the MASCOT search engine (www.matrixscience.co.uk). The monoisotopic masses of the tryptic peptides were compared to the NCBI mammalian databases using a mass tolerenace of 150-200 ppm, allowing for one missed tryptic cleavage, with carbamidomethylation of cysteine residues as a fixed modification and oxidation of methionine as a variable modification.

\subsection{Quantification of carbonyl groups and 3-NT in muscle proteins by 1-D electrophoresis and Western blotting}

Protein extracts were prepared by homogenising muscles in extraction buffer containing $20 \mathrm{mM}$ N-2-hydroxyethylpiperazine- $N$-2-ethanesulphonic acid (HEPES), $150 \mathrm{mM} \mathrm{NaCl}, 1 \mathrm{mM}$ EDTA and 5\% v/v $\beta$-mercaptoethanol. Protein content of samples was determined by using the bicinchoninic acid method (Sigma).

Detection of carbonylated proteins was performed by using Oxyblot protein oxidation detection kit as described by the manufacturer (Chemicon International). Briefly, following derivatisation with DNPH, $30 \mu \mathrm{g}$ of muscle protein was separated on $12 \% \mathrm{w} / \mathrm{v}$ acrylamide gels and transferred to PVDF membranes by semidry electroblotting.

For quantification of 3-NT in proteins, muscle powder was placed into a buffer containing $1 \mathrm{mM}$ iodoacetamide, $1 \mathrm{mM}$ benzithonium chloride, $5.7 \mathrm{mM}$ PMSF in $1 \% \mathrm{w} / \mathrm{v}$ SDS, homogenised on ice and centrifuged at $10000 \times \mathrm{g}$ for $10 \mathrm{~min}$ at $4^{\circ} \mathrm{C}$. Protein content of samples was determined by using the bicinchoninic acid method. Total cellular protein $(50 \mu \mathrm{g})$ was separated on 1-D SDS-PAGE followed by Western blotting. The content of 3-NT was again analysed by using a mouse $\mathrm{mAb}$ (Cat \# 189542) and the bands were visualised using a BioRad Chemi-Doc System (BioRad). For both carbonyl and 3-NT analysis, densitometric quantifica- 
tion of bands was undertaken. Comparisons were only made between samples on the same gel/Western blot and 3-4 samples in each group were analysed.

\subsection{Identification of protein band showing changes in 3-NT immunostaining on 1-D gel}

MALDI-TOF MS and PMF were used to identify bands on the 1-D protein gel that showed changes in 3-NT immunostaining following contractile activity or in muscles of the knockout mice in comparison with WT.

\subsection{Statistical analyses}

Results are expressed as mean \pm SEM. Multiple comparisons were carried our using one-way analysis of variance with Bonferroni modified $t$-test where appropriate. Individual comparisons were carried out using a Student's $t$-test. A $p$-value of less than 0.05 was considered significant.

\section{Results}

\subsection{Identification of oxidised proteins in skeletal muscle by 2-DE}

A representative CBB-stained gel and a carbonyl blot from quiescent GTN of adult WT mice are shown in Figs. 1A and $\mathrm{B}$, respectively. A negative control in which the sample was not reacted with DNPH showed no positive bands on the blot (not shown in detail).

PMF resulted in the identification of a number of proteins that contained carbonyl groups in GTN muscle of adult WT mice. Table 1 summarises those proteins and their location on the blot is shown in Fig. 1B.

These data demonstrate that beta-enolase and albumin are the predominant carbonylated proteins present in GTN muscle of adult WT mice. In addition, creatine kinase, fructose-bisphosphate/aldolase $\mathrm{A}$ and carbonic anhydrase III were also identified as containing detectable carbonyl groups.

\subsection{Identification of nitrated proteins by 2-DE}

A representative 3-NT blot is shown in Fig. 1C. Negative control blots in which the primary antibody to 3-NT was omitted showed no positive bands (data not shown in detail). PMF-identified carbonic anhydrase III, glyceraldehyde-3phosphate dehydrogenase (GAPDH), beta-enolase and pyruvate kinase (identified using sequence tags generated by MS/MS (Q-TOF Micro, Waters) as the major proteins containing detectable 3-NT residues in muscle of WT adult. In addition, proteins such as creatine kinase and albumin, as well as aconitase (also identified by tandem MS) also contained detectable levels of 3-NT residues (Table 2). Approximately half of the total spots submitted to MALDI-TOF-MS generated good spectra but database searching of the mass spectra of these proteins did not indicate that they were specific for a single protein; thus these proteins could not be unequivocally identified and are not presented in Table 2.

\subsection{Effect of contractile activity, ageing or lack of key antioxidant enzymes on protein carbonyls and nitrotyrosines}

Examination of 2-D carbonyl blots and 3-NT blots obtained from muscles of the groups of adult WT mice immediately postcontractile activity compared with resting adult WT, old WTmice compared with adult WTand adult Sod1 $1^{-1-}$, Sod $2^{+/-}$ or GP $\times 1^{-1-}$ mice compared with WT did not reveal any significant changes in the pattern of oxidised proteins detected, but it appeared that there were some differences in the level of the oxidation observed. When carbonyl or 3-NT blots from 2-D gels were exposed in the visualisation system for the same length of time, differences in the spot intensity of different proteins were apparent between the samples from different experimental groups. Quantitative comparisons of 2-D carbonyl or 3-NT blots between samples from the different groups were not possible and quantification was undertaken using a 1-D approach.

\subsection{Detection and quantification of protein carbonyls in skeletal muscles of mice}

In order to quantify the carbonyl content of proteins, muscle soluble proteins were separated by 1-D SDS-PAGE and the proteins were analysed for carbonyl content following Western blotting (Figs. 2A and B). Individual bands were quantified by band densitometry. Muscles from four mice in each group were analysed and only samples run on the same gel/ Western blot were compared.

The carbonyl blot revealed eight major bands of MW $\sim 25$ (band 1), $~ 30$ (band 2), 35 (band 3), $\sim 40$ (band 4), $\sim 45$ (band 5), $\sim 50$ (band 6), $\sim 70$ (band 7) and $\sim 160$ (band 8) kDa (Fig. 2A). None of these bands were detectable in a negative control (not reacted with DNPH) samples. A comparison between muscles from adult Sod $1^{-1-}$, Sod $2^{+/-}$ or GP $\times 1^{-1-}$ mice and muscle from adult WT mice is shown in Fig. 2A and a comparison between muscles of adult and old WT mice immediately after the contraction protocol and adult and old WT mice at rest is shown in Fig. 2B.

The densitometry revealed no major differences in the carbonyl content of any of the protein bands between quies-

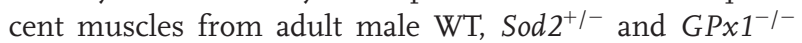
mice. In contrast, quiescent GTN muscles from adult male Sod $1^{-1-}$ mice demonstrated reduced intensity for bands 2, 3 and 4 ( $\sim 30, \sim 35$ and $\sim 40 \mathrm{kDa}$ respectively) compared with those from adult male WT mice. No effect of either age or contractile activity was seen on the intensity of any of the carbonyl bands (Fig. 2B). 
A

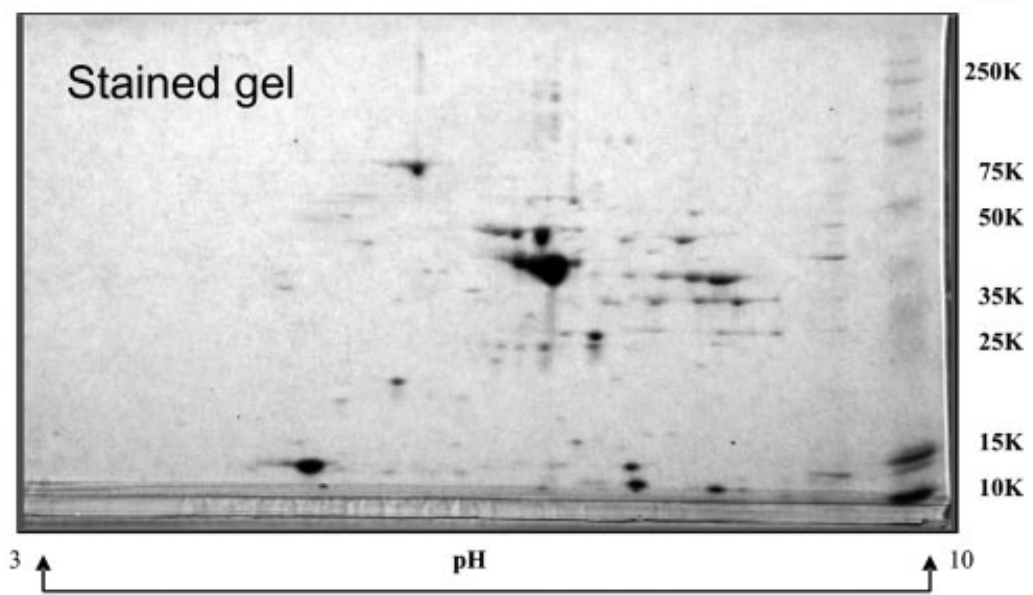

B

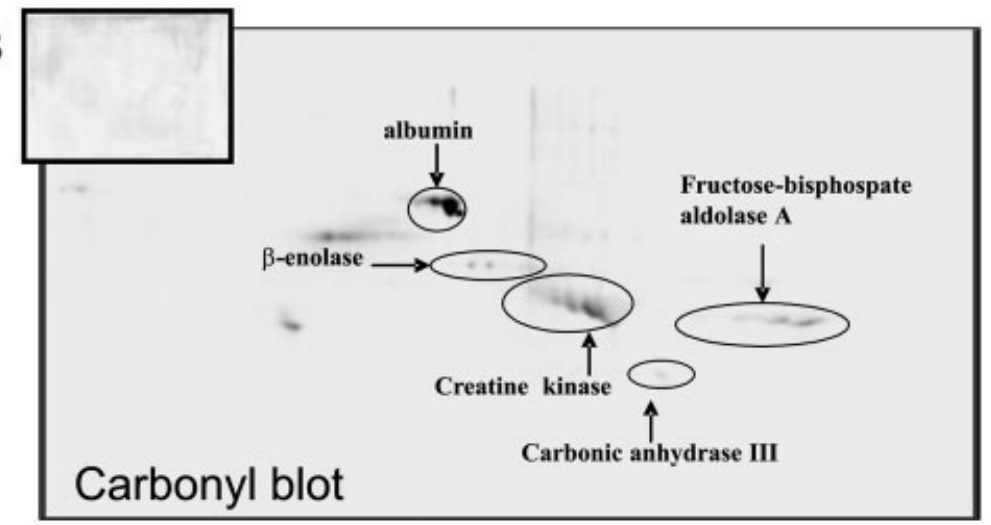

c

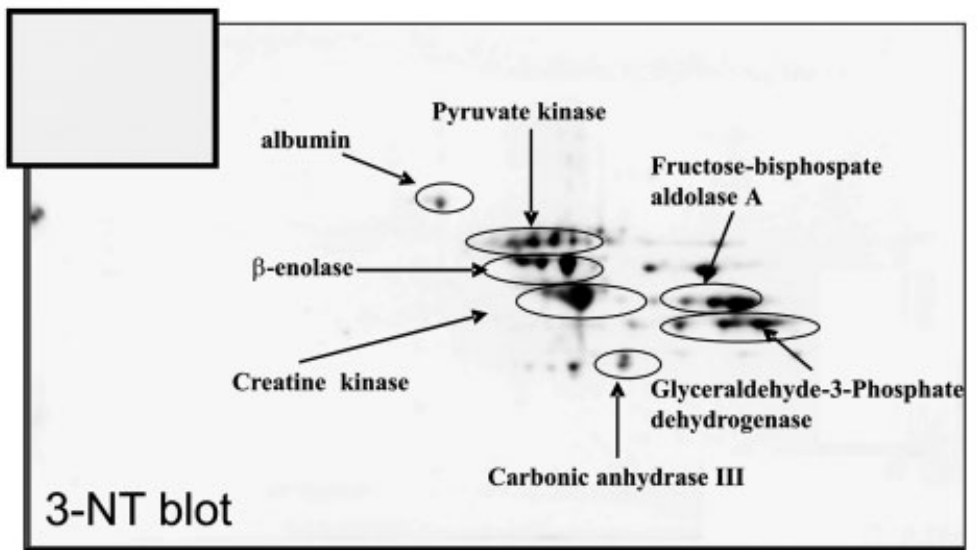

MW

$250 \mathrm{~K}$

$75 \mathrm{~K}$

$50 \mathrm{~K}$

$35 \mathrm{~K}$

$25 K$

$15 \mathrm{~K}$

$10 \mathrm{~K}$

Figure 1. 2-DE and immunodetection. Representative (A) CBB-stained gel, (B) carbonyl blot and (C) 3-NT blot. The $\mathrm{pH}$ gradient used for IEF and MWs of standards are indicated for the stained gel. At least two replicates were performed for each analysis. The insets to Figs. A and B show reduced-size images of control Western blots for the same muscle samples in which the primary antibody was omitted.

Table 1. Carbonylated proteins identified by 2-DE and MALDI-TOF

\begin{tabular}{llllll}
\hline Identified proteins & $\begin{array}{l}\text { MASCOT } \\
\text { score }\end{array}$ & $\begin{array}{l}\text { Matching } \\
\text { peptides }\end{array}$ & $\begin{array}{l}\text { Sequence } \\
\text { coverage (\%) }\end{array}$ & $\begin{array}{l}\text { Calculated } \\
\text { p/ }\end{array}$ & $\begin{array}{l}\text { Nominal } \\
\text { mass }(D a)\end{array}$ \\
\hline $\begin{array}{l}\text { B-Enolase } \\
\text { Fructose bisphosphate aldolase A }\end{array}$ & 160 & 12 & 41 & 6.81 & 47206 \\
Carbonic anhydrase III & 133 & 10 & 49 & 8.39 & 39656 \\
Albumin & 91 & 6 & 39 & 6.97 & 29502 \\
Creatine kinase & 128 & 10 & 21 & 5.75 & 70700 \\
& 163 & 13 & 42 & 6.58 & 43246 \\
\hline
\end{tabular}


Table 2. Proteins containing 3-NT residues identified by 2-DE and MALDI-TOF

\begin{tabular}{lcclll}
\hline Identified proteins & $\begin{array}{l}\text { MASCOT } \\
\text { score }\end{array}$ & $\begin{array}{l}\text { Matching } \\
\text { peptides }\end{array}$ & $\begin{array}{l}\text { Sequence } \\
\text { coverage (\%) }\end{array}$ & $\begin{array}{l}\text { Calculated } \\
\text { p/ }\end{array}$ & $\begin{array}{l}\text { Nominal } \\
\text { mass }(D a)\end{array}$ \\
\hline $\begin{array}{l}\text { s-Enolase } \\
\text { Carbonic anhydrase III }\end{array}$ & 160 & 12 & 41 & 6.81 & 47206 \\
GAPDH & 91 & 6 & 39 & 6.97 & 29502 \\
Albumin & 145 & 10 & 45 & 8.44 & 36072 \\
Fructose bisphosphate aldolase A & 128 & 10 & 21 & 5.75 & 70700 \\
Creatine kinase & 133 & 10 & 49 & 8.39 & 39656 \\
& 163 & 13 & 42 & 6.58 & 43246 \\
\hline
\end{tabular}
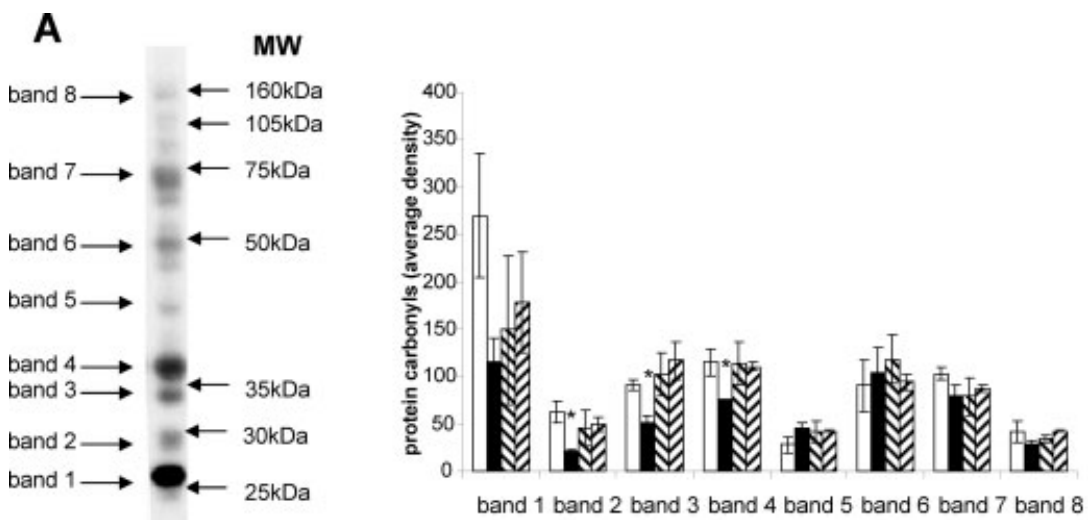

\section{B}
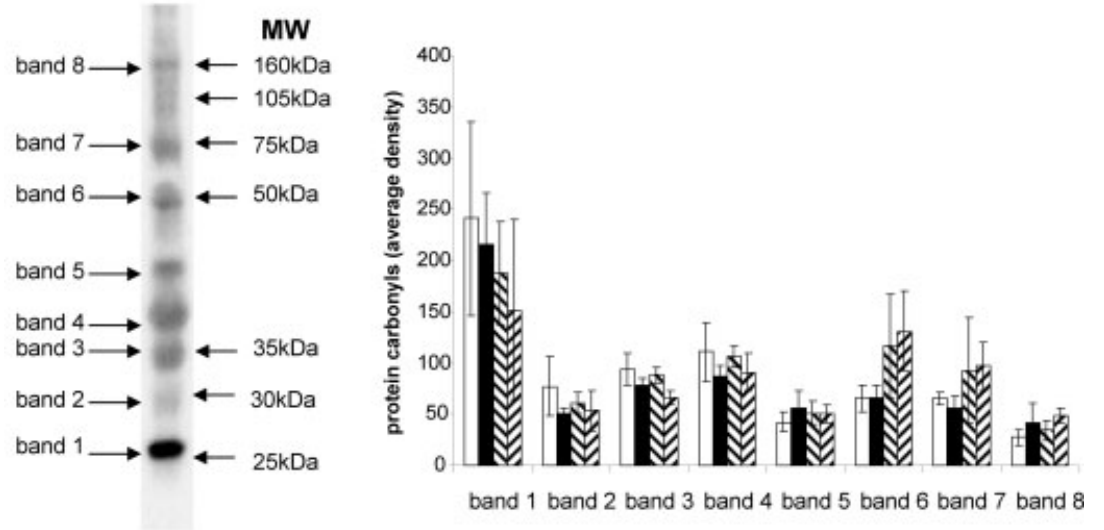

Figure 2. Quantification of protein carbonyls in quiescent GTN muscle from (A) adult male WT $(\square)$, Sod1 $1^{-1-}(\square)$, Sod2 $2^{+-}(\mathbb{N})$ and $\mathrm{GP} 1^{-1-}(\square)$ mice and (B) muscles from adult male WT ( $\square$ ) and old male WT (ם) at rest; adult male WT $(\mathbb{W})$ and old male WT $(\mathbb{Z})$ immediately postcontractions. A representative lane shows the bands detected and molecular weights (MW) are indicated. Data are presented as mean \pm SEM. ${ }^{*} P<0.05$ compared with WT male adult quiescent value at the same point.

\subsection{Detection and quantification of 3-NT in protein from skeletal muscles of mice}

In order to quantify the 3-NT content of proteins, musclesoluble proteins were separated by 1-D SDS-PAGE and the proteins were analysed for 3-NT content following Western blotting (Figs. 3A and B). Individual bands were quantified by densitometry. Muscles from four mice in each group were analysed and at least two replicates were performed for each muscle.
The 3-NT blot revealed four major bands of MW at approximately 28 (band 1), 60 (band 2), 70 (band 3) and 85 (band 4) kDa (Fig. 2A). A fifth band was also detected ( $\sim 50 \mathrm{kDa})$, but this band appeared to be nonspecific and was ascribed to an artefact of the secondary antibody used (mouse IgG heavy chain). Other bands were also present in the 3-NT blots, but due to their low intensity, quantification of these bands was not possible. Densitometry revealed a significant increase in the intensity of band $1(\sim 28 \mathrm{kDa})$ in

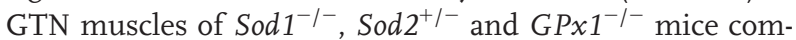




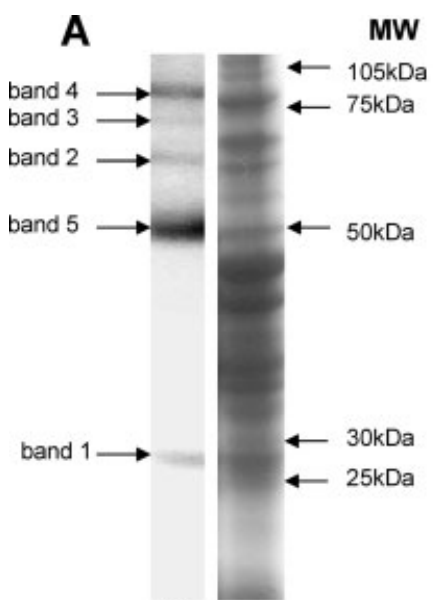

(i) (ii)



MW

C

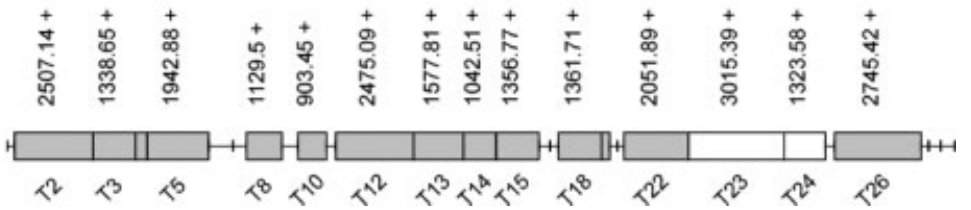

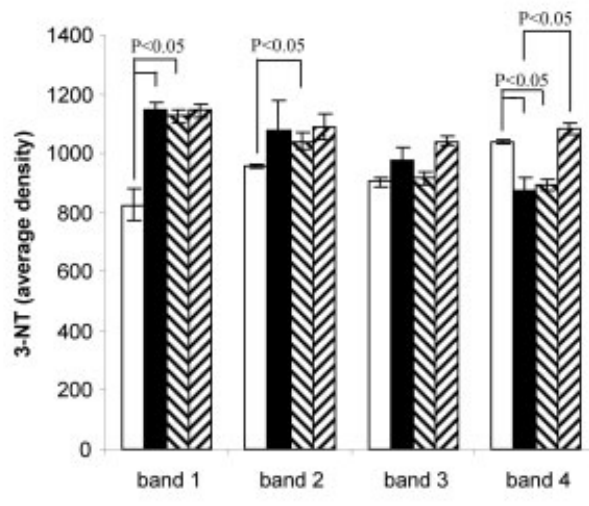

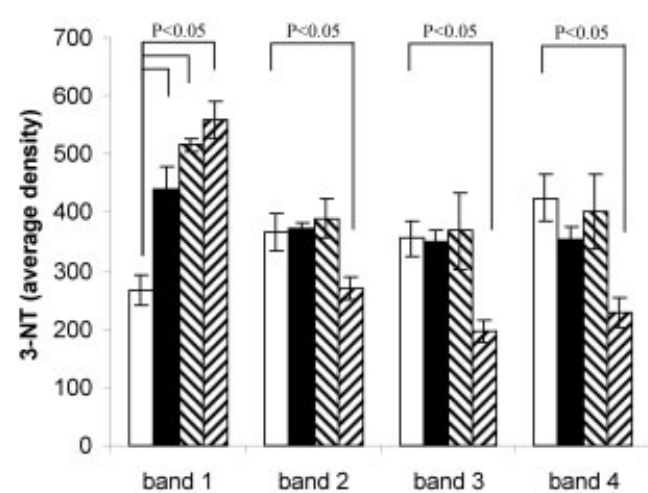

Figure 3. Quantification of 3-NT in proteins from quiescent GTN muscle from (A) adult male WT $(\square), \operatorname{Sod}_{1-1-}(\square), \operatorname{Sod}^{+/-}(\mathbb{\mathbb { N }})$ and $G P \times 1^{-1-}$ mice and (B) muscles from adult male WT ( $\square$ ) and old male WT (ם) at rest; adult male WT $(\mathbb{S})$ and old male WT (ש) immediately postcontractions. (A) Representative lanes from the western blot with the bands detected indicated (i) and the coomassie-stained gel (ii) with molecular weights (MW) indicated. For (B) only the representative lane from the western blot is shown. Data are presented as mean \pm SEM. $P$ values depicting significant differences between groups are shown in the figure. (C) Peptide coverage map of carbonic anhydrase 3 (EC 4,2,1,1) obtained from analysis of the protein band corresponding to band 1 by MALDI-TOF MS and PMF. The blocks in the peptide coverage map represent peptides between the mass range $800-$ $3500 \mathrm{~m} / \mathrm{z}$, peptides smaller than $800 \mathrm{~m} / \mathrm{z}$ are delineated by vertical ticks on the horizontal line. Shaded blocks indicate peptides observed in the MALDI-TOF mass spectrum. Monoisotopic $[\mathrm{M}+\mathrm{H}]^{+}$peptide masses for each peptide are labelled. pared with muscles from quiescent adult male WT mice (Fig. 3A). No major differences were observed between quiescent GTN muscles of adult male WT, Sod1 $1^{-1-}$ and Sod $2^{+/-}$mice for bands 2,3 and $4(\sim 60, \sim 70$ and $\sim 85 \mathrm{kDa}$ respectively). In contrast, quiescent muscles from adult male GP $\times 1^{-1-}$ mice demonstrated reduced 3-NT content for the $\sim 60, \sim 70$ and $\sim 85 \mathrm{kDa}$ bands compared with those from adult male WT mice.

The effect of age and contractile activity on 3-NT content of proteins is shown in Fig. 3B. Densitometry revealed a significant increase in band $1(\sim 28 \mathrm{kDa})$ and a significant decrease in band $4(\sim 85 \mathrm{kDa})$ in quiescent GTN muscles of old male WT mice compared with those from adult male WT mice. Contractile activity resulted in an increase in the intensity of band 1 and 2 (MW $\sim 28$ and $\sim 60 \mathrm{kDa}$ respectively) and a reduction in the intensity of band $4(\sim 85 \mathrm{kDa})$ in GTN muscles of adult male WT mice.
In contrast, in GTN muscles of old male WT mice, contractile activity resulted in an increase in the intensity of band $4(\sim 85 \mathrm{kDa})$.

Since the intensity of 3 -NT staining of band $1(\sim 28 \mathrm{kDa})$ showed consistent increases in the different physiological and pathological models, this protein was identified by MALDI-TOF MS and PMF as carbonic anhydrase III (EC 4.2.1.1) with a highly significant score of 142 and a sequence coverage of $71 \%$ (Fig. 3C).

\section{Discussion}

Theoretically, ROS can oxidise all macromolecules, including many proteins [34]. Many investigators have identified the accumulation of oxidised proteins as a key feature of ageing and of pathological conditions associated with 
increased oxidative stress [22, 35, 36]. Our investigation was designed to test hypotheses focused on measuring the number of high-abundance proteins oxidised and the degree of oxidation of proteins in GTN muscles of old WT mice, adult mice with severely compromised antioxidant systems or muscles of adult WT mice after a demanding contraction protocol, compared with quiescent muscles of adult WT mice. In addition to testing these hypotheses, our long-term goal was to identify potential targets which might provide sensitive markers of oxidative damage to proteins. Our hypothesis that only a few high abundance proteins in GTN muscles of adult mice showed oxidation was supported, but ageing, removal of major antioxidant pathways, or a challenging contractile protocol had little effect on either the number of high abundance proteins undergoing oxidative damage or the level of oxidation of the proteins identified, although the magnitude of the oxidation was consistently increased in one protein, carbonic anhydrase III.

The carbonyl assay has been widely used as a measure of oxidative damage to proteins, but is relatively nonspecific [34]. Carbonyl groups were measured by the reaction with DNPH and in the current assay the product was visualised by an antibody to dinitrophenylhydrazone. A number of ROS modify several amino acid residues, particularly histidine, arginine, lysine and proline, to produce end-products that react with DNPH [34]. Nitration of tyrosine residues occurs most commonly through a reaction with peroxynitrite. Our previous data, obtained after the 15-min contraction protocol, have indicated that skeletal muscle generates peroxynitrite, potentially due to the physical proximity of the plasma membrane superoxide-generating system and the skeletal muscle nNOS [4, 7]. The relative amounts of $\mathrm{NO}$ and superoxide generated by skeletal muscle cells have not been carefully examined previously, but most data indicate that relatively greater amounts of NO than superoxide are formed $[4,7]$, thus a rise in superoxide generation is likely to lead to increased peroxynitrite, even in the absence of any change in NO production. Superoxide appears to be one of the primary ROS generated by skeletal muscle and hence one might assume that a substantial increase in superoxide generation could lead to an increase in carbonylation of proteins, an increase in 3-NT formation, or both. Superoxide activity has been reported to be increased during contractile activity [37], with ageing [38] and assumed to be increased in Sod1 $1^{-/-}$and Sod2 $2^{+/-}$mice [29, 39]. Consequently, changes in the carbonyl content, or 3-NT groups in specific proteins were expected to provide a sensitive marker of any rise in superoxide activity.

\subsection{Nature of the major proteins containing carbonyl groups and/or 3-NTs in skeletal muscle}

Proteomic analysis identified major proteins with carbonyl groups and nitrotyrosines in skeletal muscles of mice. Surprisingly, following the contraction protocol, with ageing, or in mice lacking key antioxidant enzymes, the number of high-abundance proteins detectable on the carbonyl, or nitrotyrosine blots did not vary substantially. Despite this observation, a number of key skeletal muscle proteins were found that contained either carbonyls, 3-NT, or both. All of the oxidised proteins identified are the major cytosolic proteins in skeletal muscle. This may reflect the acknowledged limitations of the current 2-D approach to the separation and identification of proteins in complex biological tissues [17], or alternatively these proteins, present in large quantities, may act as sacrificial sinks for ROS reactions. The presence of these two modifications in adult WT mice and the lack of major changes in the physiological and genetic models indicate that these modifications are usually found in mouse skeletal muscle and are not inevitably associated with any pathophysiological process. This finding appears consistent with the increasing recognition of the roles played by ROS in normal physiology as well as pathophysiological processes [1].

In each of the different ages, activity and knockout groups studied, enolase contained both carbonyls and 3-NT. This key glycolytic enzyme catalyses the conversion of 2-phosphoglycerate into phosphoenolpyruvate. Expression of beta-enolase is restricted to striated muscles [40]. Enolase has also been identified as a target of oxidation in different diseases such as Alzheimer's [41, 42] and Huntington disease [43]. A previous study of diaphragm muscles of septic rats reported high concentrations of oxidised beta-enolase [21] and a study by Stagsted et al. [44] demonstrated that enolase is one or the major proteins that is both nitrated and carbonylated in muscles of chickens.

Oxidation of other key glycolytic enzymes, fructosebisphosphate aldolase, GAPDH and pyruvate kinase was observed in all groups studied. Aldolase A is expressed in muscle, aldolase B in liver and kidney and aldolase $\mathrm{C}$ is found predominantly in the brain [45]. Carbonylation of aldolase was reported in diaphragm muscles of septic rats [21], whereas nitration of aldolase has been reported in the liver and lungs of septic rats [46] and in skeletal muscles of adult and old rats [17]. GAPDH, which has been claimed to be a redox-sensitive enzyme of the glycolytic pathway [47], contained 3-NT residues. Previous data suggest that this enzyme may be irreversibly inactivated by peroxynitrite in rabbit skeletal muscle [48]. Pyruvate kinase was also found to contain 3-NT groups as has previously been reported for rat skeletal muscle [49].

Creatine kinase (CK), a key enzyme of cellular energy metabolism, also showed oxidation with the presence of carbonyl groups and 3-NT residues. It has been claimed that CK is a prime target for oxidative damage $[50,51]$ leading to potential inactivation of CK isoforms. Carbonic anhydrase III contained both carbonyl and 3-NT residues. Multiple carbonic anhydrase isoenzymes have been identified, all varying in developmental expression, subcellular location and tissue distribution [52], but carbonic anhydrase III is predominantly found in skeletal muscle. While the exact 
physiological role of carbonic anhydrase III is unknown, a key role in the cellular response to oxidative stress has been suggested [53].

Interestingly, an increased 3-NT in aconitase was found in the present study. Aconitase is an iron-sulphur protein that catalyses the interconversion between citrate and isocitrate during the TCA cycle. Oxidative modification of aconitase can potentially block normal electron flow to oxygen, leading to accumulation of reduced metabolites such as $\mathrm{NADH}$ and consequently can initiate a cascade with the potential to cause a dramatic increase in the cellular burden of oxidative damage [43]. Aconitase appears to be particularly sensitive to oxidative damage during ageing [54, 55]. Oxidised albumin that appeared to be derived from residual blood within the muscle tissue was also detected in each of the samples tested.

\subsection{Sensitivity of skeletal muscle proteins to oxidation}

Quantification of the amount of carbonyls and 3-NT in proteins was undertaken using 1-D SDS-PAGE and Western blotting. This revealed eight major bands (MW $\sim 25, \sim 30$, $\sim 35, \sim 40, \sim 45, \sim 50, \sim 70$ and $\sim 160 \mathrm{kDa})$ in GTN muscles for carbonyls and four for 3-NT. Comparisons with the 2-D gel allowed tentative identification of these proteins. The contractile activity, age of the mice and the knockout of key antioxidant enzymes in mice had little effect on the amount of carbonyls detected on each band, but provided very consistent changes in 3-NT contents.

A protein with a MW of $\sim 28 \mathrm{kDa}$ was nitrated more in

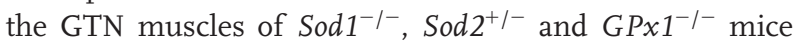
than in quiescent muscles from WT adult male mice. The same protein was also found to contain more 3-NT in muscles of old WT mice at rest and in adult WT mice following the contraction protocol. For muscles of WT adult male mice, the contraction protocol produced an increase in the 3-NT intensity of band with $\mathrm{MW} \sim 60 \mathrm{kDa}$, whereas for muscles of old WT mice, an increase in 3-NT in a protein with MW $\sim 85 \mathrm{kDa}$, likely aconitase, was observed. Analysis of the protein with $\mathrm{MW} \sim 28 \mathrm{kDa}$ on the 1-D gel using MALDI-TOF MS and PMF confirmed that it was carbonic anhydrase III (Fig. 3C). Thus, these data indicate that measurement of 3-NT groups in carbonic anhydrase III may provide a sensitive and reliable marker of oxidative stress in skeletal muscle since this was the only change that was observed in all of the models of increased oxidative stress. An increase in superoxide generation has been associated with contractile activity [2, 3, 37], ageing [56] and would be

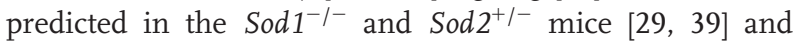
hence would be expected to increase peroxynitrite generation. In contrast, the mechanism by which a lack of GPx1, in $G P \times 1^{-1-}$ mice might lead to an increase in 3-NT formation is not immediately clear. The lack of GPx1 would be predicted to lead to a relative increase in hydrogen peroxide activity which would not immediately give rise to increased peroxynitrite, but data from Esposito et al. [57] indicated that these knockout mice have defective mitochondria with increased mitochondrial ROS generation. Hence, this may explain an apparent increase in superoxide in muscle of these mice. In addition the lack of GPx1 has been reported to lead to an increase in NO generation that may contribute to the increased nitration observed [58].

No differential effect on protein carbonyls or 3-NT was seen between a lack of the SOD predominantly in the mitochondria $\left(\operatorname{Sod} 2^{+/-}\right.$mice), or a loss from the cytosol (Sod $1^{-/-}$ mice). This may reflect the fact that mitochondrial proteins are not present in whole muscle homogenates at a sufficiently high abundance to be detected in the current system, but also concurs with other data from our laboratory that demonstrate an increased cytosolic ROS activity in muscle cells from Sod2 $2^{+/-}$mice [59].

A decline in the 3-NT content of some protein bands was observed for the GTN muscles of GP $\times 1^{-/-}$mice (bands 2, 3 and 4), in old WT mice at rest (band 4) and adult WT mice following the contraction protocol (band 4). The decline may reflect adaptations in the muscle protein composition that result from these interventions. Analagous changes may underlie the decline in carbonyls that occurred in some bands (2, 3 and 4) of Sod $1^{-1-}$ mice.

Compared with the quiescent GTN muscles of adult and old male WT mice and of GTN muscles of adult mice following the contraction protocol, no increase was observed in carbonyl formation in any of the protein bands in muscles of Sod $1^{-1-}$, Sod2 $2^{+-}$or GPx $1^{-1-}$ mice. This observation was surprising since the use of less specific methods had indicated an overall increase in the amount of carbonyls detected in proteins in ageing human brain cells [60], the ageing human eye [61] as well as in ageing house flies [62]. In skeletal muscle, Mecocci et al. [63] demonstrated a modest increase in the overall protein carbonyl content in biopsies from healthy humans. Previous data from our laboratory have also shown an age-related accumulation of protein carbonyls [19]. The differences between these studies and our current results may reflect the specificity of the current assay to soluble individual proteins. Thus, if increases had occurred in proteins not seen on the gel (i.e. potentially proteins with low abundance) these may not have been detected with the current techniques.

In summary, our data support the conclusion that protein carbonylation and/or formation of 3-NT in skeletal muscle affects major proteins involved in glycolysis (aldolase, beta-enolase and GAPDH) as well as regulation of ATP metabolism (creatine kinase) and hydration of $\mathrm{CO}_{2}$ (carbonic anhydrase III), but that only formation of 3-NT in carbonic anhydrase III occurred reproducibly in diverse models of oxidative stress in skeletal muscles.

This study was supported by a United States National Institute on Aging-funded Program Project (AG-20591). Instrumentation in the PFG was supported by the BBSRC. 


\section{References}

[1] Jackson, M. J., Philos Trans R. Soc. Lond. B. Biol. Sci. 2005, 360, 2285-2291.

[2] Reid, M. B., Shoji, T., Moody, M. R., Entman, M. L., J. Appl. Physiol. 1992, 73, 1805-1809.

[3] McArdle, A., Pattwell, D. M., Vasilaki, A., Griffiths, R. D., Jackson, M. J., Am. J. Physiol. (Cell Physiol) 2001, 280, C621-C627.

[4] Pattwell, D. M., McArdle, A., Morgan, J. E., Partridge, T. A., Jackson, M. J., Free Radic. Biol. Med. 2004, 37, 1064-1072.

[5] Balon, T. W., Nadler, J. L, J. Appl. Physiol. 1994, 77, 25192521.

[6] O'Neill, C. A., Stebbins, C. L., Bonigut, S., Halliwell, B., Longhurst, J. C., J. Appl. Physiol. 1996, 81, 1197-1206.

[7] Close, G. L., Ashton, T., McArdle, A., Jackson, M. J., Free Radic. Biol. Med. 2005, 39, 1460-1467.

[8] Silveira, L. R., Pereira-Da-Silva, L., Juel, C., Hellsten, Y., Free Radic Biol. Med. 2003, 35, 455-464.

[9] McArdle, A., van der Meulen, J., Close, G. L., Pattwell, D., Van Remmen, H. et al., Am. J. Physiol. (Cell Physiol.) 2004, 286, C1152-C1158.

[10] Gutteridge, J. M., Halliwell., B. Ann. N. Y. Acad. Sci. 2000, 899, 136-147.

[11] Radak, Z., Asano, K., Inoue, M., Kizaki, T., Oh-Ishi, S. et al., J. Appl. Physiol. 1995, 79, 129-135.

[12] Klebl, B. M., Ayoub, A. T., Pette, D., FEBS Lett. 1998, 422, 381-384.

[13] Close, G. L., Ashton, T., Cable, T., Doran, D., MacLaren, D. P., Eur. J. Appl. Physiol. 2004, 91, 615-621.

[14] Vasilaki, A., McArdle, F., Iwanejko, L. M., McArdle, A,Mech. Ageing Dev. 2006, 127, 830-839.

[15] Poppeck, D., Grune, T., Antiox. Redox Signal 2006, 8, 173184.

[16] Stuart, J. A., Brown, M. F., Biochim. Biophys. Acta 2006, $1757,79-89$.

[17] Kanski, J., Alterman, M. A., Schöneich, C., Free Radic. Biol. Med. 2003, 35, 1229-1239.

[18] Mansouri, A., Muller, F. L., Liu, Y., Ng, R., Faulkner, J. et al., Mech. Ageing Dev. 2006, 127, 298-306.

[19] Broome, C. S., Kayani, A. C., Palomero, J., Dillmann, W. H., Mestril, R. et al., FASEB J. 2006, 20, 1549-1551.

[20] Haycock, J. W., MacNeil, S., Mantle, D., Neuroreport. 1998, 9, 2201-2207.

[21] Barreiro, E., Gea, J., Di Falco, M., Kriazhev, L., James, S. et al., Am. J. Respir. Cell. Mol. Biol. 2005, 32, 9-17.

[22] Levine, R. L., Stadtman, E. R., Exp. Gerontol. 2001, 36, 14951502.

[23] Ghezzi, P., Bonetto, V., Proteomics 2003, 3, 1145-1153.

[24] Dalle-Donne, I., Rossi, R., Giustarini, D., Milzani, A., Colombo, R., Clin. Chim. Acta 2003, 329, 23-38.

[25] Barreiro, E., Gea, J., Matar, G., Hussain, S. N., Am. J. Respir. Cell Mol. Biol. 2005, 33, 636-642.

[26] Reaume, A. G., Elliott, J. L., Hoffman, E. K., Kowall, N. W., Ferrante, R. J. et al., Nat. Genet. 1996, 13, 43-47.

[27] Li, Y., Huang, T.-T., Carlson, E. J., Melov, S., Ursell, P. C. et al., Nat. Genet. 1995, 11, 376-381.
[28] Esworthy, R. S., Mann, J. R., Sam, M., Chu, F. F., Am. J. Physiol. 2000, 279, G426-G436.

[29] Van Remmen, H., Salador, C., Epstein, C. J., Richardson, A., Arch. Biochem. Biophys. 1999, 363, 91-97.

[30] Vasilaki, A., Mansouri, A., Remmen, H., van der Meulen, J. H., Larkin, L. et al., Ageing Cell 2006, 5, 109-117.

[31] Lowry, O. H., Rosebrough, N. J., Farr, A. L., Randall, R. J., J. Biol. Chem. 1951, 193, 265-275.

[32] Conrad, C. C., Choi, J., Malakowsky, C. A., Talent, J. M., Dai, R. et al., Proteomics 2001, 1, 829-834.

[33] Simpson, D. M., Beynon, R. J., Robertson, D. H. L., Loughran, M. J., Haywood, S., Proteomics 2004, 4, 524-536.

[34] Halliwell, B., Gutteridge, J. M. C., Free Radicals in Biology and Medicine, Oxford University Press, Oxford 1989.

[35] Harman, D., J. Gerontol. 1956, 11, 298-300.

[36] Dalle-Donne, I., Scaloni, A., Giustarini, D., Cavarra, E., Tell, G. et al., Spectrom. Rev. Mass 2005, 24, 55-99.

[37] Davies, K. J. A., Quintanilha, A. T., Brooks, G. A., Packer, L., Biochem. Biophys. Res. Commun. 1982, 107, 1198-1205.

[38] Lass, A., Sohal, B. H., Weindruch, R., Forster, M. J., Sohal, R. S., Age 1998, 21, 83-84.

[39] Muller, F. L., Song, W., Liu, Y., Chaudhuri, A., Pieke-Dahl, S. et al., Free Radic. Biol. Med. 2006, 40, 1993-2004.

[40] Keller, A., Ott, M. O., Lamandé, N., Lucas, M., Gros, F. et al., Mech. Dev. 1992, 38, 41-54.

[41] Castegna, A., Aksenov, M., Thongboonkerd, V., Klein, J. B., Pierce, W. M. et al., J. Neurochem. 2002, 82, 1524-1532.

[42] Sultana, R., Boyd-Kimball, D., Poon, H. F., Cai, J., Pierce, W. M. et al., Neurobiol. Aging 2005, 27, 918-925.

[43] Perluigi, M., Poon, H. F., Maragos, W., Pierce, W. M., Klein, J. B. et al., Mol. Cell Proteomics 2005, 4, 1849-1861.

[44] Stagsted, J., Bendixen, E., Andersen, H. J., J. Agric. Food Chem. 2004, 52, 3967-3974.

[45] Freemont, P. S., Dunbar, B., Fothergill-Gilmore, L. A., Biochem. J. 1988, 249, 779-788.

[46] Aulak, K. S., Miyagi, M., Yan, L., West, K. A., Massillon, D. et al., Proc. Natl. Acad. Sci. 2001, 98, 12056-12061.

[47 ] Hyslop, P. A., Hinshaw, D. B., Halsey, W. A., Jr., Schraufstatter, I. U., Sauerheber, R. D. et al., J. Biol. Chem. 1988, 263, 1665-1675.

[48] Souza, J. M., Radi, R., Arch. Biochem. Biophys. 1998, 360, 187-194.

[49] Kanski, J., Hong, S. J., Schoneich, C., J. Biol. Chem. 2005, 280, 24261-24266.

[50] Konorev, E. A., Hogg, N., Kalyanaraman, B., FEBS Lett. 1998, 427, 171-174.

[51] Castegna, A., Aksenov, M., Aksenova, M., Thongboonkerd, V., Klein, J. B. et al., Free Radic. Biol. Med. 2002, 33, 562-571.

[52] Kim, G., Lee, T. H., Wetzel, P., Geers, C., Robinson, M. A. et al., Mol. Cell Biol. 2004, 24, 9942-9947.

[53] Raisanen, S. R., Lehenkari, P., Tasanen, M., Rahkila, P., Harkonen, P. L., Vaananen, H. K., FASEB J. 1999, 13, 513-522.

[54] Yan, L. J., Levine, R. L., Sohal, R. S., Proc. Natl. Acad. Sci. U.S.A. 1997, 94, 11168-11172.

[55] Das, N., Levine, R. L., Orr, W. C., Sohal, R. S., Biochem. J. 2001, 360, 209-216.

[56] Lass, A., Agarwal, S., Sohal, R. S., J. Biol. Chem. 1999, 272, 19199-19204. 
[57] Esposito, L. A., Kokoszka, J. E., Waymire, K. G., Cottrell, B. et al., Free Radic. Biol. Med. 2000, 28, 754-766.

[58] Fu, Y., McCormick, C. C., Roneker, C., Lei, X. G., Free Radic. Biol. Med. 2001, 31, 450-459.

[59] Vasilaki, A., Csete, M., Pye, D., Lee, S., Palomero, J. et al., Free Radic. Biol. Med. 2006, 41, 1729-1735.
[60] Smith, C. D., Carney, J. M., Starke-Reed, P. E., Oliver, C. N., Stadtman, E. R. et al., Proc. Natl. Acad. Sci. U.S.A. 1991, 88, 10540-10543.

[61] Garland, Exp. Eye Res. 1990, 50, 677-682.

[62] Sohal, R. S., Agarwal, S., Dubey, A., Orr, W. C., Proc. Natl. Acad. Sci. U.S.A. 1993, 90, 7255-7259.

[63] Mecocci, P., Fano, G., Fulle, S., MacGarvey, U., Shinobu, L. et al., Free Radic. Biol. Med. 1999, 26, 303-308. 